\title{
Editorial
}

\section{Obstetrical and Neonatal Perspectives on Prematurity}

\author{
Tracy A. Manuck, MD ${ }^{1}$ Ravi Mangal Patel, MD, MSc ${ }^{2}$ \\ ${ }^{1}$ Division of Maternal Fetal Medicine, Department of Obstetrics and \\ Gynecology, University of North Carolina, Chapel Hill, North Carolina \\ 2 Division of Neonatology, Department of Pediatrics, Emory University \\ School of Medicine and Children's Healthcare of Atlanta, Atlanta, \\ Georgia
}

Am J Perinatol 2016;33:221.

Premature birth before 37 weeks of gestation is the most common cause of infant mortality worldwide. ${ }^{1}$ Many preterm infants who survive are impacted by both short- and long-term morbidity. Efforts by obstetricians and neonatologists have led to significant advances in reducing preterm birth and improving outcomes. In 2014, infant mortality in the United States was the lowest on record. ${ }^{2}$ However, additional work is still urgently needed to reduce the burden of preterm birth on patients, families, and society. We believe that this work requires strong collaboration between obstetricians and neonatologists. We selected topics for this theme issue with this goal in mind. This issue highlights current evidence as it relates to pressing topics on premature birth in the fields of obstetrics and neonatology.

We begin with an obstetric perspective examining the hypotheses regarding basic etiologies of preterm birth by reviewing genetics and normal and abnormal placentation. Next, an exploration of the importance of clinical phenotype reviews the importance of bridging clinical characteristics with basic science when critically investigating prematurity. Four clinically oriented articles examine several scenarios frequently encountered in daily practice: management of the short cervix, appropriate use of progesterone for prematurity prevention, tocolysis in the modern era, and optimizing care of a woman with a prior preterm birth. Finally, we offer a review of the global perspective on preterm birth, recognizing that low- and middle-income countries bear a disproportionate burden of this disease.

It is clear that preterm birth may not be prevented. For these pregnancies, we provide the reader with several neonatal articles. Two articles highlight and summarize important outcomes among infants born prematurely, with one focused on late- and moderately preterm infants and the other on extremely preterm infants. We hope these articles will provide the readers with a context for the frequency and spectrum of short- and long-term adverse outcomes that may affect preterm infants, while informing them with the most up-to-date evidence. Toward our goal of improving collaborative care, we include two articles that summarize interventions that can be used by both obstetricians and neonatologists to improve perinatal outcomes as it relates to optimizing delivery room care and protecting the fragile brains of our most immature infants.

In conclusion, we are excited about the recent progress in both obstetrics and neonatology and proud to highlight these accomplishments here in this special issue. Continued success depends on commitments and collaborations from national and international leaders across obstetric and pediatric disciplines, to continue to move clinical care and research forward, with the ultimate goal of further reducing the burden of prematurity.

\section{References}

1 Blencowe H, Cousens S, Oestergaard MZ, et al. National, regional, and worldwide estimates of preterm birth rates in the year 2010 with time trends since 1990 for selected countries: a systematic analysis and implications. Lancet 2012;379(9832): 2162-2172

2 Murphy SL, Kochanek KD, Xu JQ Arias E. Mortality in the United States, 2014. NCHS Data Brief, No 229. Hyattsville, MD: National Center for Health Statistics; 2015

\footnotetext{
Address for correspondence Ravi Mangal Patel, MD, MSc, Division of Neonatology, Department of Pediatrics, Emory University School of Medicine and Children's Healthcare of Atlanta, 2015 Uppergate Dr. NE, Atlanta GA 30322 (e-mail: rmpatel@emory. edu; ravipatelmd@gmail.com).
}

Copyright @ 2016 by Thieme Medical Publishers, Inc., 333 Seventh Avenue, New York, NY 10001, USA. Tel: +1(212) 584-4662.
DOI http://dx.doi.org/ 10.1055/s-0036-1571853. ISSN 0735-1631. 